\title{
Social Media for Political Mobilization in India: A Study
}

\section{Meti $\mathbf{V}^{1 *}$, Khandoba $\mathrm{PK}^{2}$ and Guru $\mathrm{MC}^{3}$}

${ }^{1}$ Department of Journalism and Mass Communication, Gulbarga University, Jnana Ganga, Gulbarga, Karnataka, India

${ }^{2}$ Department of Communication and Journalism, University of Mysore, Mysuru, Karnataka, India

\begin{abstract}
The media plays a vital role in a democracy; informing the public about political issues and acting as a watchdog against abuses of power. During election campaigns the media provides information and analysis about the political parties' programmes, policies, candidates and performance. Electronic communication seems to make politicians seem more remote; there is still no connection between politics where power is brokered, and the network society itself.

In a similar way, social media has also transformed politics in India and globally. Its effect has impacted the way candidate campaign for their election. Social media allows politicians and political parties a method to connect directly with people across the country at a reduced cost and greater reach than traditional media. Social media is not simply the next in a line of communications technologies: it has also changed everyday activities and connected people in a manner never before possible.

The paper aims to examine the extent use of social media by the political parties to promote their image and political messages, among their supporters and peoples in social media. The paper intends to examine how people consume the political issues or political discussion on social media. It was studied on the basis of the responses received from a sample of 100 respondents in Hyderabad Karnataka region. Results reveal interesting information on the types of social media used the ratings of the most used social media and their impact on society.
\end{abstract}

Keywords: Social media; Online political communication; Political parties; Facebook; Twitter; Youtube; Social media and politics

\section{Introduction}

Social media was a popular word in Indian parliament election 2014. Political parties use social media because traditional mass media communication medium are highly regulated by election commission of India. For over a decade politicians have taken the web in an attempt to better reach voters in our new media society. At first it was the use of static webpage to promote campaign goals, promises and information. However, as social media or the social networking sites (SNS) began to rise in popularity in the mid-2000, campaigns began in earnest attempting to harness their power to reach more voters.

For instance, the 2008 U.S. presidential election was the benchmark as the first election to fully grasp the power and reach of the SNS's to impact voters. The U.S. President, Barack Obama's campaign used Facebook in an exceptional ways to reach out the young voters. It worked, allowing him to win the votes nearly 70 percent of voters that were under 25 years old [1].

Social media is also facilitating a new way by which people are able to search and share information and increasing their awareness [2]. It plays a vital role in converting street movements into large cities of Romania in 2012 [3]. In the same passion during anti-corruption movement 2012, social activist, Anna Hazare used social media to connect people in New Delhi.

Politicians use social media to communicate with their audience and to call them either to protest, or to vote [3]. So, the use of Web 2.0 technologies has made it incredibly easy for a wide range political parties, social activist, individual leaders are getting attention towards social media.

In addition to the impact that social media has for campaigns in the traditional sense of expanding the reach of their message to more voters and often younger voters. Social media activities can be either used to predict the outcome of elections. However, many companies have attempted to use the data which is available from the social media sites such as Facebook, Twitter, Google Plus and other platforms to predict election outcomes. It is assumed that people visits these social media platforms with their ideas and thoughts regarding their political leaders during the election periods. While through careful content and structural network analysis these platforms will provide similar results to traditional election polling.

Hence, social media has emerged as an essential tool of communication and has created new ways of political mobilizing and encourage social media users in political activities ranging from joining their political groups by tweeting, status update, expressing supports through blogs and videos on Youtube.

Political campaigning has become a major focus in the growing field of social media studies. Researchers across the globe analyse political online communication. This analysis aims to identify how the political parties managed to mobilize social media users by means of the communicating through social networks sites, blogs and videos on Youtube.

\section{Classification of social media}

Social media technologies take on many different forms

*Corresponding author: Meti V, Ph.D Researcher, Department of Journalism and Mass Communication, Gulbarga University, Jnana Ganga, Gulbarga, Karnataka, India, Tel: 97399732221; E-mail: vijaymeti007@gmail.com

Received April 12, 2015; Accepted September 25, 2015; Published September 30, 2015

Citation: Meti V, Khandoba PK, Guru MC (2015) Social Media for Political Mobilization in India: A Study, J Mass Communicat Journalism 5: 275. doi:10.4172/2165-7912.1000275

Copyright: (C) 2015 Meti V, et al. This is an open-access article distributed under the terms of the Creative Commons Attribution License, which permits unrestricted use, distribution, and reproduction in any medium, provided the original author and source are credited. 
including blogs, business networks, enterprise social networks, forums, microblogs, photo sharing, products/services review, social bookmarking, social gaming, social networks, video sharing and virtual worlds.

The development of social media started off with simple platforms such as sixdegrees.com. Unlike instant messaging clients such as ICQ and AOL's AIM, sixdegrees.com was the first online business that was created for real people, using their real names. However, the first social networks were short-lived because their users lost interest. The Social Network Revolution has led to the rise of the networking sites. Research shows that the audience spends $22 \%$ of their time on social networking sites, thus proving how popular social media platforms have become.

\section{Social media and its uses in India}

Social media is playing a considerable new role in Indian democracy. With the changing politics of India political parties and politicians have found a new ways of reaching out to a younger and aspiration population.

The use of social media by Indians was first highlighted during the 2008 Mumbai attacks when information shared through Twitter and Flickr between Indians and the outside [4]. "The second mass use of social media in India was the May 2009 national elections, when, for the first time, online voter registration and transparency campaigns started" where first time political parties tried to reach out to voters through social networking websites [4].

However, all of these are still in trend, but increasingly in urban India, political parties are becoming tech savvy as this is the only way to reach out eloquent youths. Among major political parties in India, BJP has the biggest charisma in social media. BJP started using the social media even before 2009 general election, which it lost. But in recent years, it has dig deeper into social media. Several senior leaders like Sushma Swaraj, Rajnath Singh, Arun Jaitley, Narendra Modi and many are on social networking sites. Narendra Modi as the BJP's prime ministerial candidate for the 2014 general election has his own team for his social media management [5].

Social media has also credited with helping the new Aam Aadmi Party and its candidate, Arvind Kejriwal, won a surprise victory in Delhi against major political parties. But social media can also be subject to significant abuse. Some politicians have been accused of boosting their apparent popularity on social media with legions of followers who don't exist and of using social media to smear their opponents. Worse, social media have been used to fan violence against religious and ethnic groups.

\section{Functions of social media as a new tool in Indian general election 2014}

In the context of relationship between politicians, social media and public, identifies number of functions that Internet have as follows:

- $\quad$ Politicians promote their controlled speech and present their point of view without being interrupted by journalists or by media format limitation.

- $\quad$ Social media has given privilege for politicians to post a presumptive political agenda.

- $\quad$ By means of social media, political parties or politicians can mobilize public and invites them to participate in discussion on some issues of public interest.
- $\quad$ By using the social media tools, politicians and political parties interacts apparently with more efficiently with their supporters, beyond institutional and bureaucratic rigors.

\section{Signification of the study}

The social media have practically buried the physical and social gaps. They are also considered as horizontal media of communication. They provide the benefits of participatory democracy and development in modern society. Modern political parties have utilized the social media to enhance their political strategies and gain public support. The political parties have also joined the 'cyber world' mainly to multiply political transactions and engineer the support of various sources.

Presently, emphasis is laid on the setting of ever lasting relationship between political parties and people. Social media practice is one of several forms of political communication and needs to be examined from the point of view of 'social engineering'.

In this age of paradigm shift, new media practices are required to focus the attention of the people on electioneering process with special reference to Parliament Elections - 2014.

\section{Criticisms of social media}

Criticisms of social media range from criticisms of the ease of use of specific platforms and their capabilities, disparity of information available, issues with trustworthiness and reliability of information presented, the impact of social media use on an individual's concentration, ownership of media content, and the meaning of interactions created by social media. Although some social media platforms offer users the opportunity to cross-post simultaneously, some social network platforms have been criticized for poor interoperability between platforms, which leads to the creation of information silosisolated pockets of data contained in one social media platform However, it is also argued that social media have positive effects such as allowing the democratization of the internet while also allowing individuals to advertise themselves and form friendships. Others have noted that the term "Social" cannot account for technological features of a platform alone, hence the level of sociability should determine by the actual performances of its users.

\section{Objectives}

The major objective of the present study is to understand the intervention of social media in Parliament Elections - 2014. The specific objectives of the present study are as follows:

- To identify the various social media platforms used by the respondents.

- To understand the popularity of social media platforms.

- To identity the popular social media platform used by respondents for political awareness.

- To study the impact of social media on society.

\section{Methodology}

Survey method will help to collect data from each sample. According to Kraemer Survey research quantitatively is use to describe certain aspects of a given population. These aspects typically include the examination of the relationship between variables. Second, survey data needed for research, therefore, are relative gathered from people. Finally the research results of the survey can be returned to the general population from which a selected portion of the population uses. 
Citation: Meti V, Khandoba PK, Guru MC (2015) Social Media for Political Mobilization in India: A Study. J Mass Communicat Journalism 5: 275. doi:10.4172/2165-7912.1000275

Page 3 of 4

Survey method is selected as it is well planned. It can be generalized and can be statistically analysed. To meet the requirement of the study Two-way stratification sampling was adopted for data collection from the target population.

The scope of the study comes under the selected cities in the Hyderabad Karnataka region. Questionnaire method has been followed to collect the data from users of the study in which 120 questionnaires were distributed and then total 100 respondents equally consisting 50 male and 50 female respondents were selected randomly from them.

\section{Results and Discussion}

Table 1 shows that 50 are male respondents and 50 are female respondents covered in the study. Majority of the respondents covered are in the age group between 26 to 40 years of age, 38.0 per cent of respondents are under the age category 18 to 25 years of age and the rest 19.0 per cent belongs to age group of 40-60 years (Table 2).

The above table (Table 3 ) clearly shows the maximum numbers of respondents are of social media sites such as Facebook, Twitter, MySpace and many more. While, the least 4 per-cent of respondents are unaware of social media platforms.

According to the above Table 4, less than half of the respondents found to use social media between two and three hours (48 per cent). 18.0 per cent prefer using less than two hours, 15.0 per cent for 4-5 hours and 19.0 per cent members prefer for more than 5 hours per day.

The above table clearly shows that Facebook is the most popular social networking sites among respondents (63 per cent) than other SNS followed by twitter (24.0 per cent) and Google Plus 9 per cent, while the least LinkedIn is used by only 4 per cent of respondents Tables 5 and 6.

The above table shows that majority of the respondents 62 per cent

\begin{tabular}{|l|c|c|}
\hline Sex & Respondents & Percent \\
\hline Male & 50 & 50.0 \\
\hline Female & 50 & 50.0 \\
\hline Total & 100 & 100.0 \\
\hline
\end{tabular}

Table 1: Gender of the Respondents.

\begin{tabular}{|l|c|c|}
\hline Age (in years) & Respondents & Percent \\
\hline $18-25$ & 38 & 38.0 \\
\hline $26-40$ & 43 & 43.0 \\
\hline $40-60$ & 19 & 19.0 \\
\hline Total & 100 & 100.0 \\
\hline
\end{tabular}

Table 2: Age of the Respondents.

\begin{tabular}{|l|c|c|}
\hline Awareness & Respondents & Percent \\
\hline Yes & 96 & 96.0 \\
\hline No & 04 & 04.0 \\
\hline Total & 100 & 100.0 \\
\hline
\end{tabular}

Table 3: Awareness on Social Media Sites.

\begin{tabular}{|l|c|c|}
\hline Hours (in a Day) & Respondents & Percent \\
\hline Less than 2 hours & 18 & 18.0 \\
\hline 2-3 hours & 48 & 48.0 \\
\hline 4-5 hours & 15 & 15.0 \\
\hline More than 5 hours & 19 & 19.0 \\
\hline Total & 100 & 100.0 \\
\hline
\end{tabular}

Table 4: Hours Spent on Social Media.

\begin{tabular}{|l|c|c|}
\hline SNS & Respondents & Per cent \\
\hline Facebook & 63 & 63.0 \\
\hline Twitter & 24 & 24.0 \\
\hline Linkedln & 04 & 04.0 \\
\hline Google Plus & 09 & 09.0 \\
\hline Total & 100 & 100.0 \\
\hline
\end{tabular}

Table 5: Preferred Social Media Sites.

\begin{tabular}{|l|c|c|c|}
\hline Purpose & Yes & No & Total \\
\hline Entertainment & 56 & 44 & 100 \\
\hline Creating Groups and Community & 49 & 51 & 100 \\
\hline To Get Updated News & 41 & 59 & 100 \\
\hline Sharing Files With Friends and Family & 43 & 57 & 100 \\
\hline Making New Friends & 46 & 54 & 100 \\
\hline Connecting With Old Friends & 62 & 38 & 100 \\
\hline Others & 22 & 78 & 100 \\
\hline
\end{tabular}

Table 6: Purpose of Social Media Use.

\begin{tabular}{|l|c|c|}
\hline Preference & Respondents & Percent \\
\hline Facebook & 32 & 32.0 \\
\hline Twitter & 46 & 46.0 \\
\hline Linkedln & 07 & 07.0 \\
\hline Google Plus & 15 & 15.0 \\
\hline Total & 100 & 100.0 \\
\hline
\end{tabular}

Table 7: Popular Social Media Format To Consume Political Information.

\section{Political Parties}

Bharatiya Janata Party (BJP)

Indian National Congress (INC)

Aam Aadmi Party (AAP)

\begin{tabular}{|c|c|c|}
\hline Yes & No & Total \\
\hline 93 & 07 & 100 \\
\hline 69 & 31 & 100 \\
\hline 89 & 11 & 100 \\
\hline
\end{tabular}

Table 8: Popular Political Party on Social Media.

prefer SNS to connect with old friends, followed by entertainment (56 per cent) like videos and images, creating groups and communities (49 per cent), making new friends (46 per cent), Sharing Files With Friends and Family (43 per cent) and To Get Updated News (41 per cent). However, only 22 per cent of respondents indicate that they use social media for other purpose such as purely personal purpose, business promotions - to connect with customers and marketing.

According to the Table 7, majority of respondents 46 per cent prefer the micro-blogging site, Twitter, for political information as most of the Indian politicians tweets their latest political updates. Followed by 32 per cent prefer Facebook, 15 per cent for Google Plus while only 7 per cent prefer LinkedIn.

According to the above Table 8 Bharatiya Jantaa Party is the most popular political party on social media platforms with 93 per cent, while Arvind Kejriwal's Aam Aadmi Party ranks second and the Indian National Congress is third popular political party in social media with 89 per cent and 69 per cent respectively.

The Table 9 clearly shows that the Indian Prime Minister Narendra Modi (94 per cent) is the popular political figure on social media sites. Followed by the twitter minister, Shashi Tharror ( 78 per cent), the former Prime Minister Dr. Manmohan Singh (73 per cent). While, Sushma Swaraj (67 per cent) and Arvind Kejriwal (65 per cent) are popular leaders on social media.

Social media sites come with positive and negative impact on society. According to the Tables 10 and 11; it is clear that connecting 
Citation: Meti V, Khandoba PK, Guru MC (2015) Social Media for Political Mobilization in India: A Study. J Mass Communicat Journalism 5: 275. doi:10.4172/2165-7912.1000275

\begin{tabular}{|l|c|c|c|c|}
\hline Political Leaders & Party Affiliation & Yes & No & Total \\
\hline Narendra Modi & BJP & 94 & 06 & 100 \\
\hline Dr.Manmohan Singh & INC & 73 & 27 & 100 \\
\hline Arvind Kejriwal & AAP & 65 & 35 & 100 \\
\hline Shashi Tharoor & INC & 78 & 22 & 100 \\
\hline Sushma Swaraj & BJP & 67 & 33 & 100 \\
\hline
\end{tabular}

Table 9: Popular Political Leader on Social Media.

\begin{tabular}{|l|c|c|c|}
\hline Purpose & Yes & No & Total \\
\hline Businesses Communication & 20 & 80 & 100 \\
\hline A Platform for Writers & 53 & 47 & 100 \\
\hline Speedy Communication & 83 & 17 & 100 \\
\hline Connects Friends & 92 & 08 & 100 \\
\hline Finding Common Ground In An Open Society & 37 & 63 & 100 \\
\hline In Touch With The World & 73 & 27 & 100 \\
\hline Building Relationships & 88 & 12 & 100 \\
\hline
\end{tabular}

Table 10: Impact of Social Media on Society (Positive).

\begin{tabular}{|l|c|c|c|}
\hline Purpose & Yes & No & Total \\
\hline Addiction & 78 & 22 & 100 \\
\hline Pornography & 68 & 32 & 100 \\
\hline A False Sense of Connection & 53 & 47 & 100 \\
\hline Cyber-bullying & 49 & 51 & 100 \\
\hline Privacy & 84 & 16 & 100 \\
\hline Bad for Our Culture & 26 & 74 & 100 \\
\hline Spoils Relationships & 71 & 29 & 100 \\
\hline
\end{tabular}

Table 11: Impact of Social Media on Society (Negative).

friends is the major positive aspect of the social media, while privacy is the major concern for disliking the social media sites.

Other positive aspects as preferred by respondents are building relationships ( 88 per cent), speedy communication ( 83 per cent), in touch with the world ( 73 per cent), platform for writers ( 53 per cent), finding common ground in an open society (37 per cent) and business communication (20 per cent).

Negative aspects are addiction for social media (78 per cent), spoils relationships (71 per cent), pornography (68 per cent), false sense of connection (53 per cent), cyber-bullying ( 49 per cent) and bad for our culture (26 per cent).

\section{Conclusion}

The purpose of this study is to understand to what extent social media use for political activities influences political efficacy, political knowledge, and political participation among peoples in Hyderabad Karnataka region.

The results show that the use of social media for political activities influences peoples' political efficacy, political knowledge, and political participation. The study also shows that social media users may discover political activities in social media and by this way intensify their political knowledge, increase their political efficacy, and improve their political participation. Moreover, the social media usage for political activities was influenced by frequency of general social media use. The more often they use social media, the more often they use social media for political activities.

The study shows that, for those who discussed the election on Twitter, the role of the web in this regard is significantly stronger than that of the mass media. Twitter attracts a very peculiar subset of citizens, who differ from the population writ large in terms of demographic characteristics. Engaging with politics through the web is conducive to greater face-to-face involvement and the propagation of digitally acquired information through interpersonal interaction, and these effects seem to occur regardless of the individual's social and demographic characteristics. The findings suggest the possibility that as more begin to use social media to discuss politics; we will begin to see even more offline discussion of politics [6].

The results suggest that what happens online does not stay online, but rather moves offline and affects citizens' face-to-face conversations. To the extent that this is true, the political demands that are articulated through social media will become harder to ignore for anyone who is interested or involved in the political process, including those who are inclined to study it.

\section{References}

1. Dutta S, Fraser M (2008) Barack obama and the Facebook election. U.S. News and World Report.

2. Akar $E$ (2011) An examination of the factors influencing consumers attitudes toward social media marketing. Journal of Internet Commerce 10: 35-67.

3. Antonio M (2013) Social Media- PR Tools for Romanian Politicians? Procedia - Social and Behavioral Sciences 81: 116-121.

4. Open Source Centre (2010) OSC Media Aid: Overview of Leading Indian Social Media.

5. Stoffer T (2014) The Use and Impact of Social Media in Political Elections. University of Maryland, College Park.

6. https://en.wikipedia.org/wiki/Social_media 